\title{
Gender Issues in Disaster: Understanding the Relationships of Vulnerability, Preparedness and Capacity
}

\author{
Mirza Ali Ashraf ${ }^{1, *}$, Md. Abul Kalam Azad ${ }^{2}$ \\ ${ }^{1}$ Ministry of Disaster Management and Relief, Bangladesh Secretariat, Bangladesh \\ ${ }^{2}$ Institute of Disaster Management and Vulnerability Studies, University of Dhaka, Bangladesh
}

Copyright (C) 2015 by authors, all rights reserved. Authors agree that this article remains permanently open access under the terms of the Creative Commons Attribution License 4.0 International License

\begin{abstract}
The aim of the study is to explore the gender issues in disaster and to understand the relationships between vulnerability, preparedness and capacity following a qualitative method on the basis of secondary sources. The study notes that the women living in coastal areas are facing more difficulties due to the complexity of atmosphere where their activities are not properly recognized in disaster planning and management. However, the study showed that women, particularly belong to the poor families are primarily responsible for their domestic roles due to culturally dominated labour division. The study also recommended that women should be involved in emergency planning and disaster management process through ensuring their active participation. The inclusion of greater number of women in the emergency management profession could help in the long term to address disaster risks. Since, the underlying cultural, social, and economic patterns that lead to a low socio-economic status of women and thereby generate their specific vulnerability to disasters. Though, such initiatives have not addressed like their entire adverse impact on socio-economic status in recent literature, the present study is an initiative to address the women's involvement in preparedness and capacity building at the community level as well as household level which the vulnerable women are striving with the frequent disasters to sustain in the planet.
\end{abstract}

Keywords Gender, Disaster, Capacity, Vulnerability and Preparedness

\section{Introduction}

The term gender has become synonymous with women ([23], [21]). But, gender is not just about women, as often implicitly presumed, it deals with the roles of both women and men [10]. Enarson and Chakrabarti [11] stated that gender dimension is not optional - it is a central dimension of all efforts to develop more sustainable and safe ways of organizing life on the planet. They also said that disasters are no more gender blind than the economic, political, social and environmental development decisions that produce them. Ariyabandu [2] showed in her writing, how the relation of gender and sex in societies invariably augment the vulnerability of women in disasters. However, the needs of women are generally overlooked in the relief and recovery processes and their capacities and skills are not used as a resource in emergency management and planning [11].But, it is evident that women can act of agents of change, who are generally marginalized[33].Thus, the need of the hour is to ensure gender equality in disaster reduction policies and measures by promoting women to be increasingly involved in roles such as leadership, management and decision making as well as recognizing women's position in their community and the larger society [11].

\section{Gender}

Gender, the state of being male or female typically used with reference to social and cultural differences rather than biological ones [27]. Moser [23] stated that the differences between women and men within the same household and within and between cultures that are socially and culturally constructed and change over time. He also described that these differences are reflected in: roles, responsibilities, access to resources, constraints, opportunities, needs, perceptions and views held by both women and men. Enarson and Chakrabarti [11] stated that sex and gender are never automatically the primary social facts on the ground nor are this ever in play in isolation from other facts of life. Moser [23] argued that gender is not a synonym for women but, considers both women and men and their interdependent relationships. Moreover, gender is also never irrelevant and must always be examined and reflected in practice, for men and boys as much as women and girls [11]. 


\section{Disaster and Gender Based Vulnerabilities}

Before going to review academic definitions and concepts of disaster, the literal meaning of disaster is quite straight forwardly linking with losses of (human) life. According to the Oxford Dictionary [27], the definition of disaster is “... a sudden accident of a natural catastrophe that causes great damage or loss of life." To understand a disaster, we need to understand the components of vulnerability of different groups of people, and relate these to the hazard risk [6].They added that disaster is also related to people's resilience, particularly to their livelihoods - how quickly and easily they can resume activities that earn money or provide food and other basics. Cannon [8] stated that at the severity of a disaster is, therefore, a reflection both of the location and intensity of the hazard, and the number of people of different levels and types of vulnerability. Further, he argued that vulnerability differs according to the 'initial conditions' of a person - how well-fed they are, what their physical and mental health and mobility are, and their morale and capacity for self reliance.

Dijkhorst and Vonhof [10] said that a hazard only turns into a disaster when the vulnerability of people is high. However, disaster happens only when a natural hazard impacts negatively on vulnerable people [8]. The people with poor access to (natural) resources have a less developed fall back position in case of emergency, which automatically lead to a greater risk [10]. In addition, there are many factors such as poverty, environmental degradation and unequal power relations that influence the extent of disaster impacts [10]. Moreover, disaster impact is contingent on the vulnerability of affected people, which can and often does systematically differ across economic class, ethnicity, gender, and other factors [25].

\subsection{Gender Issues in Disaster}

Gendered experiences give women a distinctive starting point for critiquing familiar assumptions from the position of the oppressed [13]. Fordham [13] also stated that male-dominated management and universalized experiences of disasters have stimulated most gender research to focus on women specifically rather than on affected people including both men and women because of their relative invisibility in the whole process of disaster management. Ariyabandu [2] observed that gender based prejudices and cultural divisions mainly affect women. Ariyabandu [2] also noted that existing socio-structural biases mean women are always more vulnerable in the aftermath of a disaster, in terms of security and safety (see Box 1).The magnitudes of disasters are partially influenced by political, economic and socio-cultural contexts [33]. However, she added that mainstreaming gender into disaster reduction policies and measures translates that context into identifying the ways in which women and men are positioned in society.
Box 1. Key Gender issues in Disasters

- Women and men are vulnerable to disasters in different ways due
to social and economic reasons.
Due to pre-existing gender relations, within the same social
group/class women are poorer and more vulnerable in
comparison to men of the same category.
Impacts of disasters are different on men and women-in terms of
survival, death, trauma and recovery.
Needs and priorities of women and men in different stages of the
disaster cycle are different (biological, family, social and
cultural).
Gender-based prejudices view women as weak, passive,
incapacitated victims in need of rescue in crisis situation,
although in reality women of different age groups play an active
role.
Gender-based identities view men as strong and capable who
require least assistance.
Due to gendered identities, women's vulnerability get
highlighted, capacities and skills get masked.
Due to gendered identities, vulnerabilities of men are not visible
and not recognized.
Women and men have different skills and capacities resulting
from gender-based roles and responsibilities and gender-based
division of labour.

(Source: Ariyabandu, [3])

Several studies disclose that women, as a result of care giving are at greater risk in many disastrous situation, as they must stay with, assist, protect, and nurture family members ([3], [30], [33]).Valdes [33] described that focus simply on women's activities can obscure important dimensions of their livelihood strategies that include cooperation and interdependence between men and women. Byrne and Baden [7] speak of gender conflict as a result of a focus on women alone as victims. Saad [30] stated that gender difference tend to be disappear temporarily during and immediate after the disaster. She also noted that once the community settles after the disaster, women tend to suffer greater consequences than men as they can lose their privacy and income generating activities, with little mobility to seek their jobs as they are always tied to their families. According to Valdes [33], disaster reduction policies and measures need to be implemented with at two fold aims: to enable societies to be resilient to natural hazards, while ensuring that development efforts decrease the vulnerability to these hazards.

\subsection{Gender Perspective and Approach in Disaster}

Gender perspective highlights women's capacities and can indicate where opportunities are missed by relief interventions for making aid more effective by supporting and developing women's skills and capacities [7]. But, the one sided focus on women, instead of gender, may have some negative consequences [10]. However, Byrne and Baden [7] opinioned that it is necessary to ask the following two questions at the time of integrating a gender perspective in disaster into relief intervention:

- Do interventions serve to further weaken women's access to and control over resources? or 
- Do they support women's capacity to cope with crises, enhance their skills and provide them with the means to rebuild their lives?

Gender is an important consideration regarding formation of different relations which supported by family, culture and state [8]. It is important to note that a gender perspective not only addresses women's practical needs before, during and after disasters, but also looks at the responsibilities of men and women and the relations between them [10]. Gender approach in disaster risk reductions built on the understanding the both women and men are part of the same society [33]. Valdes [33] also told that this does not mean they have the same rights, education and options neither in normal times nor when a disaster strikes. However, gender approach is a social, cultural and personal construct, not biological; separate from the sex-based categories of male/female [25].

\subsection{Gender Relations and Inequality in Disaster}

Gender relations refer to social relations between men and women [7]. The social interactions between men and women in society result in socially constructed roles, responsibilities and identities for men, women, girls and boys [3]. According to Ariyabandu [3], some of the key factors include biological, sexual and socio-cultural factors which are reflected in gender relations in communities and societies (see Box 2) while Valdes [33] described that gender relations are part of the social and cultural context that shape a community's ability to anticipate, prepare for, survive, cope with and recover from disasters. Basically, gender roles are learned through socialization processes; they are not fixed but changeable [8].

Box 2. Gender relations in society

Gender relations in society are broadly reflected in

identities: a combination of physical and behavioral characteristics which set apart boys from girls, men from women;

perceptions: views as to how they are differentiated in their roles as men and women;

attitudes: actions guided by the perceptions and

status: the place occupied by the men and women in family, community and society.

(Source: Ariyabandu, [3])

Gender relations come into effect in all spheres of life: personal, social, economic and political; they are not equitable and always unfavorable and prejudiced towards girls and women [3]. On other hand, vulnerability to hazards and to gender involves a complex interaction between poverty and gender relations, in which women are likely to experience higher levels of vulnerability than men [8]. It is found that both self and social protections are also affected by gender issues in time of disaster.

Neumayer and plumper [25] noted that natural disasters do not affect people equally. It is extremely difficult to predict that how the increased disaster impacts will affect women in particular. In terms of the socio-cultural aspects, there are processes which make the experience of girls and women quite different from that of boys and men [3]. Like this, the biological reproductive function itself makes women more vulnerable before, during and disaster aftermath as compared to men. Not only that, societal attitudes restricting interaction between men and women [25]. In addition, they stated that biological and physiological differences between the sexes are unlikely to explain large-scale gender differences in disaster situation (see Box 3). That is why, women more reluctant to congregate in the public cyclone shelters where they are forced to interact with other men in time and aftermath of disaster [29]. There are specific gendered factors which is essential to take into account in order to reduce the vulnerability of women [32]. It is evident that the cultural norms constrained women access to emergency warnings and cyclone shelters. Both self and social protection is also affected by gender issues related to 'culture' [8].

Box 3. Three main causes for gender differences in disasters

From a conceptual perspective, it seems most fruitful to distinguish between three main causes for gender differences in mortality vulnerability to natural disasters:

First, biological and physiological differences between men and women may at times disadvantage women in their immediate response to the disaster.

Second, social norms and role behavior may lead to a behavior of women that increases their vulnerability in the immediate course of the disaster.

And third, disasters may lead to shortage of resources of basic need as well as a temporary breakdown of social order, in which case the competition between individuals becomes fiercer and existing forms of gender discrimination become exacerbated and new forms of discrimination can emerge.

With the exception of the biological and physiological reasons, the higher vulnerability of women is socially constructed and is due to differences in the socio-economic status of men and women.

(Source: Neumayer and Plumper [25])

Cultural factors which produce gender inequality are need to be addressed for instance, so that women can adequately seek shelter without shame and harassment, and are not condemned to poverty and increased vulnerability when widowed or divorced [8]. Relief operations conforming to prevailing gender norms may in their routine practice further disempowered women, for example, when cultural norms inhibit women from visibly accessing public relief [5]. However, disaster period provides space to address more structural unequal gender roles, as disaster has a profound effect on gender relations. Leaving this responsibility up to development projects may mean that traditional roles and divisions could soon be reinforced after disaster [10]. They also stated that there is a dual rationale for promoting gender equality firstly, that equality between women and men equal rights, opportunities and responsibilities - is a matter of human rights and social justice and secondly, that greater equality between women and men is also a precondition for sustainable people-centered disaster management system. 


\subsection{Gendered Disaster Risk and Vulnerabilities}

Gender specific dependencies and vulnerabilities based on reproductive differences are relevant in disasters, because of the respective ability of women and men to participate in household, community and decision making about hazards and risk [33]. In the 1991 cyclone in Bangladesh, for example, women were highly overrepresented among the 120,000 killed [17]. There were reports about the fact that so many women had died in relation to men during tsunami. In a briefing note Oxfam [27] stated that in certain areas of Ache 80 percent of the victims were female. Data from India and Sri Lanka also showed a significant difference in the way the disaster affected people along the gender-lines. There had been several reasons for which women were much affected; as men were fishing at sea the waves went under their boats, whereas the women had remained home, some of them waiting ashore to collect, clean and sell the fish their men took home [27]. Ariyabandu [3] stated that as women were tending to their children when the waves hit, they had to cling on to their children and save them, leaving them little power to safe themselves. There have been some added effects on a societal level with so many female casualties. Young girls, whose mothers have died, are dropping out of school to take care of their families [27]. However, the difference in vulnerabilities between men and women during the tsunami pertained to physical abilities, women's roles as caretakers for the children, and livelihoods [3].

Poverty is both a cause of vulnerability, and a consequence of hazard Impacts [8]. However, since being female is strongly linked to being poor, unless poverty is reduced, the increase in disasters and extreme climate events linked with climate change is likely to affect women more than men [8]. It is evident that the impacts of disasters are worse for women are inconclusive or variable. Because of, women are responsible for the family property and were afraid of the blame and punishment if anything happened to it in their absence [5]. Dijkhorst and Vonhof [10] stated that central role in everyday life on the one hand and lacking decision-making power and access to resources on the other, make women to a great extent vulnerable to natural disasters. Vulnerability can be considered to have five components: namely, the initial conditions of a person, the resilience of their livelihood, their opportunities for self-protection, and their access to social protection and social capital [6]. It is observed that those components vary from higher to lower levels according to political and social factors affecting different groups of people.

In developing countries women face greater vulnerabilities than men. Vulnerability in Bangladesh correlates strongly with poverty, and it is widely accepted that women make up a disproportionate share of poor people [8]. Fordham [13] claiming, women's greater vulnerability is based on the fact that, in general, women and girls are disadvantaged compared to men and boys. However, according to IASC (1999), well-documented field practice has shown that gender-sensitive humanitarian assistance can help in mitigating the different and negative effects of complex emergencies and natural disasters on men and women (see Box 4). A report of ILO [18] points out, women's subordination is a root cause of their disaster vulnerability. With respect to this subordinated position, their economic insecurity, ideological constraints, male dominance, sexual and domestic violence, extensive care-giving responsibilities, and heterosexist practices and kinship relations are mentioned as factors that contribute to women's vulnerability [10].

Box 4. Understanding gendered vulnerabilities

Inter Agency Standing Committee (IASC) has identified six main
areas of gender concerns that need to be addressed in humanitarian
assistance. To understand gendered vulnerabilities the followings might
be addressed accordingly:
Prevention of Violence and Protection;
Targeting and Relief Distribution;
Health and Reproductive health;
Nutrition and Household Food Security;
Income Generation and Skill Training;
Disaggregated Data, Information and Advocacy Materials.

(Source: IASC, 1999 [18])

Blaikieet al. [6] pointed that gendered vulnerability does not derive from a single factor, such as household headship or poverty, but reflects historically and culturally specific patterns of relations in social institutions, culture and personal lives. However, intersecting with economic, racial and other inequalities, these relationships create hazardous social conditions placing different groups of women differently at risk when disastrous events unfold [6]. Anderson [1] argued that gender is certainly not the only factor determining vulnerability. Cannon [8] predicted if there is no serious progress in reducing poverty, then it can be assumed that women will become increasingly affected by the impact of intensified hazards, in terms of their ability to resist and recover from them. Byrne and Baden [7] assumed that there is a danger that women become invisible in relief programmes if gender is not considered. It is evident that men receiving most resources and participating in the planning and implementation of programmes. This can lead to increase gender inequality and may also hamper the effectiveness of relief programmes. However, women's capacities remain under-utilized and their needs not being met. But, according to observation of Greet [16], women are generally the chief providers of food and emotional security in most family situations. He also passed comment that those strengths should be highlighted rather than undermine them, as would many 'quick response' programmes [16]. Bangladesh is one of the few countries in the world where men live longer than women and where the male population outnumbers the female [4]. It is estimated that 90 per cent of the victims of the 1991 cyclone disasters were women and children [32]. However, NGO activities to increase understanding and make warnings more effective seem to have improved this over the past ten years in Bangladesh [15]. 


\section{Gender, Resilience Capacity and Preparedness}

\subsection{Gender in Disaster Preparedness}

Preparedness is the stage involving pre-disaster preparation efforts and many mitigative actions [14]. Traditionally, women perform many activities that are associated with emergency preparedness [10]. It is also noted that women are excluded from emergency planning and preparedness decisions in the developing world. Basically, women and men are performed distinct preparedness activities and women are largely absent in formal emergency preparedness [14]. Dijkhorst and Vonhof [10] argued, the increase of women's work burden in times of crisis may also lead to a reduction in their participation in the public sphere. It is observed that women become active in grassroots organizations through female friendship networks. Along with this disasters pose a threat to the home and community thus, women are seen as an extension of their domestic roles and responsibilities [14]. However, women are often considered strong and capable in the wake of, during and after a disaster, and they are also regarded as belonging to the most vulnerable people [10]. In Bangladesh, for example, rural women are rarely included in planning of preparation of disaster plans, an inclusion would improve the women's socio-economic wellbeing [19].

Local community knowledge, strong social networks, key roles in families, and active work roles make women resourceful actors in crises, but it is observed that women are rarely recognized by 'front-line' responders [18]. Moreover, women are markedly absent in the decision making process, leadership roles, and higher levels of emergency management field [22]. Saad [31] suggested that preparedness campaigns should reflect knowledge of the roles women play in the family and community. Greet [16] argued that despite the gender concerns spelled out in policy documents of relief organizations, women's needs and roles in production and development are still being marginalized in development and disaster practice. In disaster situations, traditional tasks become more complex and are performed under difficult conditions, but also new tasks arise [10]. They also noted that active role of women, even more proactive than the role of men, in disaster preparation and mitigation, and emergency response activities. Ikeda [17] argued, due to social isolation women were not able to make information on how to minimize the risk. However, Palmer and Zwi [28] discussed about the involvements of women throughout the whole programme in disaster situation starting from preparedness to finish. They expect, that will increase women's self-esteem, give them access to health services and reduce their exposure to risk [28].

\subsection{Gender in Aid Distribution and Rehabilitation}

The distribution of aid was unequal, in the sense that aid was directed towards male-headed households [12]. It is evident that there was a lack of participation of women in post-disaster recovery planning. In addition, it is also noted that [12] officials turned away some widows seeking compensation for their lost husbands because they could not produce the body. This simply shows what type of unexpected situation being faced by women at the time of disaster. According to Oxfam [26], widowed women had trouble in obtaining benefits and cash, due to the system that only gives out these benefits to the men as heads of the household.

Relief workers in Bangladesh trying to get emergency food and clothing to women, for example, urge agencies to put more women in the field to circumvent cultural and other barriers to gender-fair assistance [5]. It is observed that women were hardly consulted in decision-making on camp management and rebuilding houses. Chew and Ramdas [9] stated that, in post-tsunami Sri Lanka, for example, women had no say in temporary housing design. As a result, dwellings actually were constructed without any kitchen facilities. In addition, there was no gender-differentiated data or gender analysis available of which relief organizations could make use during the planning and implementation of their projects and programmes [2]. However, she stated that complex emergencies and natural disasters have a differentiated impact on men and women which often affect the realization of rights.

\subsection{Gendered Capacity and Mainstreaming Gender in Disaster}

Women often hold vital social knowledge and vast untapped capacity for reducing community risk [10]. It is also evident that women's survival and coping skills, their interpersonal networks and intimate care of most vulnerable among us and certainly their knowledge of environmental resources and ecosystems are all life savings in disasters [11]. In Florida's hurricane Andrew, for example, poor, minority were the most at risk to the storm because they lacked power, status, resources [22]. However, discrimination against women does not only accentuate women's vulnerabilities during disasters- it also wastes women's potential as source of resilience [8]. According to the $23^{\text {rd }}$ special session of UN General Assembly on Women in 2000 was focused on gender equality, development and peace for the twenty first century, and gender perspective in integrated into all disaster risk management policies, plans and decision making processes, including those related to risk assessment, early warning, information management, and education and training (UN, 2000). Beside this, Hyogo Framework for Action (HFA) 2005-2015 provides a clear commitment that can guide policy makers and the community at large to engage more systematically in reducing risk to disasters. It is evident that women-specific projects continue to play an important role in promoting gender equality [34].

Women's domestic work and responsibilities remain most 
of the time invisible for outsiders, but can be regarded as the backbone of the rural economy in developing countries [10].Therefore, the needs, strengths and relative power of various groups need to be analyzed, so that 'equitable inequalities' will be established [13]. Women-specific initiatives can create an empowering space for women and act as an important incubator for ideas and strategies that can be transferred to mainstream interventions [10]. It is expected that targeted initiatives focusing specifically on women or the promotion of gender equality are important for reducing existing disparities, serving as a catalyst for promotion of gender equality. Mishra [21] assumed that it will promote long lasting changes in attitudes, beliefs and practices by men as well as women on an equal footing, based on common understanding and experiences (see Box 5). Beside this, he focused on increased engagement of men in the movement to engender disaster relief development work [21].

Box 5. Win-win situation for gender equality

At the $48^{\text {th }}$ session of the UN Commission on the status of women
(2004), participating governments agreed to address the role of men and
boys in achieving gender quality. The governments, UN bodies and
civil society stakeholders were argued to promote action at all levels in
fields such as education, health services, training, media and the
workplace to develop and strengthen the contribution of men and boys
to attain gender quality (UNDAW 2003). There is considerable
experience behind the argument that including men and boys in this
movement is a "win-win" situation that can further hasten the process
of building gender equity at all levels to attain gender quality.

(Source: Mishra [21])

Initiatives focused on men support could be taken for the promotion of gender equality by developing male allies [21]. As gender refers to both women and men, and the relations between them, promotion of gender equality should concern to engage women as well as men. However, building capacities obviously take time but it should keep in mind that gender can make the difference between life and death [20]. That is why, men and women should be involved in the planning and execution of projects related to development, and in implementing proper mitigation measures to avoid the devastating impacts of natural disasters [31].

\section{Conclusions and Recommendations}

From the above discussion it is clear that how many women's lives are made more difficult, and as a consequence, how they are made more vulnerable in disaster situations. It has been suggested that this is happening due to the complexity of atmosphere where their activities are not properly recognized in disaster planning and management. However, literature showed that women, particularly belong to the poor families are primarily responsible for their domestic roles due to culturally dominated labour division. It is recommended that women should be involved in emergency planning and disaster management process through ensuring their active participation. The inclusion of greater number of women in the emergency management profession could help in the long term to address disaster risks. The underlying cultural, social, and economic patterns that lead to a low socio-economic status of women and thereby generate their specific vulnerability to disasters are not easy to deal with. But this does not mean that nothing can be done.

Findings from the study show that, on average, large natural disasters lower the life expectancy of women more than that of men. It is implies that policymakers, nongovernmental organizations, and the academic community need to pay closer attention to the gendered nature of disaster vulnerability women for improving socio-economic status of women. Such attention should focus on the special medical, economic, and security needs of women in the aftermath of disasters as well as on mechanisms to ensure fair and nondiscriminatory allocation of relief resources. However, developing such initiatives will not entirely prevent the adverse impact of large-scale disasters on women in societies where their everyday socio-economic status is low. But, assumed, it can reduce the excess mortality of women as well as their exposure to disasters compared to that of men in future. Finally, in conclusion of this essay, it can be noted that the impact of disaster is gendered.

\section{REFERENCES}

[1] Anderson, M.B, Understanding the Disaster-Development Continuum: Gender Analysis is the Essential Tool. In B. Walker (ed) Women and Emergencies. Oxford: Oxfam. 1994.

[2] Ariyabandu, M.M, Addressing Gender Issues in Humanitarian Practice: Tsunami Recovery. In: Special Issue for International Day for Disaster Risk Reduction. Geneva: UNISDR, 2005.

[3] Ariyabandu, M. M, Sex, Gender and Gender Relations in Disaster. In: Enarson, E. and Chakrabarti, P.G.D. (Eds.), Women, Sex and Gender. New Delhi: SAGE Publication. New Delhi: SAGE Publication, 2009.

[4] Asian Development Bank, Country Briefing Paper: Women in Bangladesh. Manila: ADB, 2001.

[5] Begum, R, Women in Environmental Disasters: The 1991 Cyclone in Bangladesh. Gender \& Development. 1(1):34-39, 1993.

[6] Blaikie, P. T. Cannon, I. D. and Wisner, B., At Risk: Natural Hazards, People's Vulnerability and Disasters. London: Routledge, 1994.

[7] Byrne, B. and Baden, S. Gender, Emergencies and Humanitarian Assistance. BRIDGE Report No 35. Sussex: IDS, 1995.

[8] Cannon, T. Gender and climate hazards in Bangladesh. Gender \& Development 10(2):45-55, 2002.

[9] Chew, L. and Ramdas, K. N. Caught in the Storm: The Impact of Natural Disasters on Women. San Francisco: The Global 
Fund for Women, 2005.

[10] Dijkhorst, H.V. and Vonhof, S. Gender and Humanitarian AidA Literature Review of Policy and Practice. Netherlands: Department of Disaster Studies, Wageningen University, 2005.

[11] Enarson, E. and Chakrabarti, P.G.D. Women, Gender and Disaster Global Issues and Initiatives. New Delhi: SAGE Publication, 2009.

[12] Fletcher, L.E. Stover and Weinstein, H. After the Tsunami: Human rights of vulnerable people. Berkeley: Human Rights Centre, University of California, 2005.

[13] Fordham, M. Gendering Vulnerability Analysis: Towards a more Nuanced Approach. In G. Frerks, G. Bankoff and D. Hilhorst Mapping Vulnerability: Disasters, Development and People. London: Earthscan, 2004.

[14] Fothergill, A. The Neglect of Gender in Disaster work: An overview of the Literature. International Journal of Mass Emergencies and Disasters.14(1): 33-56, 1996.

[15] German Red Cross. Living with cyclones: disaster preparedness in India and Bangladesh. Bonn: German Red Cross, 1999.

[16] Greet, P. Making Good Policy into Good Practice. In B. Walker (Ed) Women and Emergencies. Oxford: Oxfam UK and Irelan, 1994.

[17] Ikeda, K. Gender Differences in Human Loss and Vulnerability in Natural Disasters: A Case Study from Bangladesh. Indian Journal of Gender Studies. 2(2):171-93, 1995.

[18] ILO. Crisis, Women and other Gender Concerns Selected issues papers. Geneva: Recovery and Reconstruction department of ILO, 2002.

[19] Khondker, H. Women and Floods in Bangladesh. International Journal of Mass Emergencies and Disasters.14(3): 281-92, 1996.

[20] Mehta, M. Reducing Disaster Risk through Community Resilience in the Himalayas. In: Enarson, E. and Chakrabarti, P. G. D. (Eds.), Women, Sex and Gender. New Delhi: SAGE Publication, 2009.

[21] Mishra, P. Let's Share the Stage: Involving Men in Gender Equality and Disaster Risk Reduction. In: Enarson, E. and Chakrabarti, P.G.D. (Eds.), Women, Sex and Gender. New
Delhi: SAGE Publication, 2009.

[22] Morrow, B.H. and Enarson, E. Hurricane Andrew Through Women's Eyes: Issues and Recommendations. International Journal of Mass Emergencies and Disasters.14(1): 5-22, 1996.

[23] Moser, C. Gender Planning and Development: Theory, Practice and Training. London: Routledge, 1993.

[24] Moser, A. Gender and Indicators Overview Report, 2007. Available at: Available at: http://www.bridge.ids.ac.uk [Accessed: November 03, 2013.]

[25] Neumayer, E. and Plumper, T. The Gendered Nature of Natural Disasters: The Impact of Catastrophic Events on the Gender Gap in Life Expectancy, 1981-2002. Oxford: Blackwell publishing, 2007.

[26] Oxfam. The Tsunami's Impact on Women. Oxford: Oxfam Briefing Note, 2005.

[27] Oxford Dictionary. Oxford University Press, 2013.

[28] Palmer, C. and Zwi, A. Women, Health and Humanitarian Aid in Conflict, in Disasters. 22(3):236-249, 1998.

[29] Rashid, S.F. and Michaud, S. Female adolescents and their sexuality: notions of honour, shame, purity and pollution during the floods, Disasters. 24(1): 54-70, 2000.

[30] Rivers, J. Women and Children Last: An Essay on Sex Discrimination in Disasters. Disasters 6(4): 256-67. Focus on Gender 1(1): 34-9, 1982.

[31] Saad, S.G. Environmental Management and Disaster Mitigation: Middle Eastern Gender Perspective. In: Enarson, E. and Chakrabarti, P.G.D. (Eds.), Women, Sex and Gender. New Delhi: SAGE Publication, 2009.

[32] Schmuck, H. Empowering women in Bangladesh, 2002. Available at: http://www.reliefweb.int [Accessed: November 14, 2013]

[33] Valdes, H. M. A Gender Perspective on Disaster Risk Reduction. In: Enarson, E. and Chakrabarti, P. G. D. (Eds.), Women, Sex and Gender. New Delhi: SAGE Publication, 2009.

[34] UNISDR. Gender Perspective: Working Together for Disaster Risk Reduction: Good practice and Lessons learned. Geneva: UNISDR, 2007 